Nutr. Dieta 1968;10:80

\title{
Varia
}

\section{INTERNATIONAL COUNCIL OF NURSES}

Since August 1966, Geneva has been the headquarters of the International Council of Nurses, a world-wide organization to which 63 national nurses associations are affiliated. The Council decided to transfer its headquarters from London to Geneva so as to maintain closer relations with the World Health Organization and similar international organizations with nursing interests.

The publication of the International Nursing Review, official journal of the International Council of Nurses, is one of the Council's principle undertakings. Other publications include ICN Calling (the ICN news letter containing news of topical interest) and information leaflets in three languages, and other publications of professional interest.

In 1969, the International Council of Nurses - possibly the largest women's professional association in existence-is holding an international congress in Montreal, which nearly 12000 nurses from most parts of the world are expected to attend. 